\title{
CONF- $920808--3$
}

\section{SMALL ANGLE NEUTRON SCATTERING STUDY OF CREEP DEFORMATION AND FRACTURE OF TYPE 304 STAINLESS STEEL*}

M. H. Yoo, J. C. Ogle, J. H. Schnelbel, and $\mathrm{R}$. W. Swindeman Metals and Ceramics Division

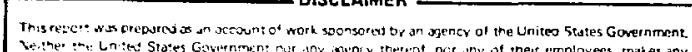

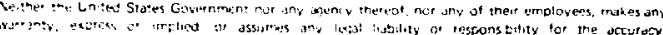

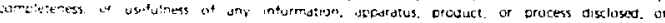

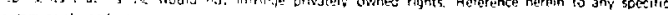

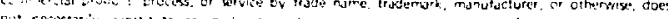

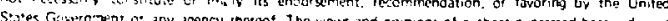
(ill
Oak Ridge National Laboratory

Oak Ridge, Tennessee 37830

\section{ABSTRACT}

COI:T-820808--3

DE\&2 020899

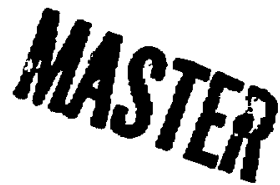

A sma1l-angle neutron scattering (SANS) study has been performed to determine the size distribution of carbide precipitates that were formed during creep deformation in type 304 stainless steel. The hardening mechanism during primary creep by a fine dispersion of carbide particles in the matrix was confirmed by the SANS measurement and also by direct TEM olservations. The size distribution of creep-induced cavities was also determined by SANS measurements after past-creep solution heat treatment.

\section{KEYWORDS}

Creep, small-angle neutron scattering, grain boundary cavitation, carbide formation, high-voltage electron microscopy.

\section{INTRODUCTION}

In austenitic st.eels, such as AISI type 304 stainless stee1, precipitation strengthening occurs because of the formation of stable carbides or nitrides in the matrix, either before or during creep service.

\footnotetext{
*Research sponsored by the Division of Materials Sciences, U.S. Department of Energy under contract W-7405-eng-2.6 with the Union Carbide Corporation.

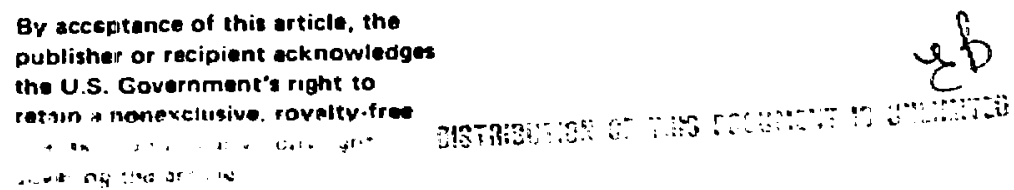


The precipitation of second phase particles on grain boundaries provides, however, preferential sites for cavity nucleation, and hence it may lead to reduced creep rupture ductility. The purpose of this paper is to Investigate quantitatively the evolution of $\mathrm{M}_{23} \mathrm{C}_{6}$ precipitates and the formation of grain boundary cavities during deformation of a heat of type 304 stainless steel (ORNL Heat 9T2796) by means of a sma11-angle neutron scattering (SANS) techrique.

\section{CREEP DEFORMATION AND FRACTURE}

The material used in this study was taken from a 16 mm bar of type 304 stainless steel with the following chemical composition (in weight percent): $\operatorname{Cr}(18.6), \mathrm{Ni}(9.5), \operatorname{Mn}(1.26), \operatorname{Si}(0.44), \operatorname{Mo}(0.35)$, $\mathrm{C}(0.059), \mathrm{P}(0.033), \mathrm{S}(0.015)$, and $\mathrm{Fe}($ balance). For creep testing rodtype specimens were machined to a reduced section of $9.5 \mathrm{~mm}$ diam and $51 \mathrm{~mm}$ length. After machining, specimens were reannealed in argor for 30 minutes at $1093^{\circ} \mathrm{C}$ and rapidly cooled. The resulting grain size was In the range of 80 to $120 \mu \mathrm{m}$, and the hardness $\left(R_{B}\right)$ was 64 .

Two specimens were creep tested at $593^{\circ} \mathrm{C}$ and $134 \mathrm{MPa}$. The test on the first specimen was continued unt 11 rupture at $16,891 \mathrm{~h}$, whereas, the test on the second was discontinued prior to the start of the tertiary creep stage at $12,100 \mathrm{~h}$. Both specimens exhibited simflar creep curves as shown in Fig. 1. An initial loading strain near $1 \%$ for both specimens was not included in Fig. 1. The shape of the creep curves is unique for stainless steel in the sense that the secondary creep rate is two to three orders of magnitude lower than the initial rate. The pronounced hardening during primary creep was due to immobilization of dislocations by a fine dispersion of $\mathrm{M}_{23} \mathrm{C}_{6}$ carbides throughout the 
matrix (Swindeman, 1979). Transmission electron microscopy (TEM)

observations confirmed this hardening mechanism, as shown in Fig. 2(a)

which shows the diameter of matrix carbides in the range of $D=20-120 \mathrm{rm}$ and the estimated number density of $\mathrm{N} \cong 2 \times 10^{20} \mathrm{~m}^{-3}$. The failure mode was Identified by optical metallography and scanning electron microscopy to be one of microvoid coalescence.

SMALL-ANGLE NEUTRON SCATTERING

SANS measurements were made on crept samples with the 30-m SANS facility at the National Center for Small-Angle Scattering -Research (Koehler, et al., 1981). The incident neutron wavelengch was $\lambda=0.475 \mathrm{~nm}$, and the range of scattering vector was $k=0.038-1.0 \mathrm{~m}^{-1}$, where $k=$ $4 \pi \sin \theta / \lambda$ and $\theta$ is the Bragg angle. The scattered intensity recorded on the two-dimensional position sensitive detector (PSD) was corrected for such parasitic effects as scattering from the empty specimen chamber, electronic noise, and non-uniform detector sensitivity. The corrected intensity was converted to a macroscopic differential scattering cross section (absolute intensity) by calibration in reference to the well-characterized coherent scattering cross section of voids in a neutron-irradiated aluminum sample (Hendricks et al., 1974). Because of the flxed size of the active area of the PSD, a wide range in scattering vector was covered easily by changing the specimen-to-detector distance, L.

SANS measurements were made on both failed and interrupted creep samples with the direction of Incident neutrons parallel to the axis of applied stress $(\underset{\sim}{x} \| \underset{\sim}{g})$. In each case, a control specimen prepared from the threaded head section was also used. Figure 3 shows the radially 
averaged scattering curve from the gage section of the interrupted sample. Data from two different sample-to-detector distances, $L=16.86 \mathrm{~m}$ and $\mathrm{L}=5.26 \mathrm{~m}$, show a very good scaling agreement over the region of $\kappa$ where over'ap occurs. Porod's Law (Porod, 1952) is well obeyed as indicated by the straight line of slope -4 in Fig. 3. Figure 4 shows that at small $\kappa\left(\kappa<0.05 \mathrm{~nm}^{-1}\right)$ the data follow Guinier's Law (Guinier, 1939).

The analytical method developed by Fedorova and Schmidt (1978) was used to calculate the size distribution of carbide precipitates from the SANS data. The numerical technique developed for an earlier SANS stuiy of fatigue-induced cavities in nicke]. (Yoo, et al., 1982) was used for the present analyses. The size distribution curve obtained by using the radius of gyration $R_{G}=53.6$ min and the forward intensity $I(0)=$ $d \sum / d \Omega(0)=1.1 \times 10^{6} \mathrm{~m}^{-1}$ is shown by curve (a) in Fig. 5. The size distribution shown by the curve (a) is consistent with the direct TEM observations as in Fig. 2(a). From the skew distribution of carbide diameters the mean diameter of $D=57.0 \mathrm{~nm}$, the total number density of $\mathrm{N}=7.7 \times 10^{19} \mathrm{~m}^{-3}$ and the volume fraction of $\Delta V / V=7.4 \times 10^{-3}$ were obtained. Each of these parameters increase slightly, only by a few percent, as the deformation is continued until creep rupture.

In order to differentiate the evolution of carbides and the formation of cavities and cracks, SANS measurements were repeated after post-creep solution heat treatment. The deformed SANS samples were annealed in argon for 30 minutes at $1093^{\circ} \mathrm{C}$ and rapidly cooled. The size distribution resulting from the subsequent SANS measurement and analysis is shown by curve (b) of Fig. 5. This result implies either undissolved carbides of $D=110 \mathrm{~m}, N=4.4 \times 10^{18} \mathrm{~m}^{-3}$, and $\Delta V / v=3.1 \times 10^{-3}$ or possibly coarsened creep cavities. Direct observation of these solution retreated 
samples by TEM (Fig. 2b) and high-voltage electron microscopy (HVEM) revealed no evidence of large size carbide particles remaining. In a limited number of foils observed so far no creep cavities have been detected.

The absolute scale of a size distribution curve depends on the difference of homogeneous scattering densities, $\Delta \rho=\rho_{p}-\rho_{m}$, between a scattering particle and the matrix, where $\rho=b / \Omega, b$ is the coherent scattering length, and $\Omega$ is the atomic volume. The value of $\Delta \rho$ for $\mathrm{M}_{23} \mathrm{C}_{6}$ carbides in type 304 stainless steel used for the analyses was $\Delta \rho^{2}=9 \times 10^{28} \mathrm{~m}^{-4}$ (Schwahn et al., 1981), and the corresponding value for cavities is $\Delta \rho^{2}=55 \times 10^{28} \mathrm{~m}^{-4}$. While the same mean diameter of $D=110 \mathrm{~nm}$ applies, an analysis with the latter value of $\Delta \rho$ gives the density of $\mathrm{N}=7.2 \times 10^{17} \mathrm{~m}^{-3}$ and a more reasonable value of the assoclated volume fraction of $\Delta V / V=5.1 \times 10^{-4}$ - See curve (c) of Fig. 5 .

\section{SUMMARY AND DISCUSSION}

The unique and powerful advantages of the SANS technique for the non-destructive evaluation of damage accumulation in deformed metals and alloys were pointed out in recent review articles (Korstortz, 1979; Weertman, 1981). In this work we have investigated the viability of the technique for studying damage accumulation in creep tested type 304 statnless steel. The present work may be summarized by the following conclusions: (a) the quantitative size distribution, the number density, and the volume fraction of $\mathrm{M}_{23} \mathrm{C}_{6}$ carbide precipitates were obtained by SANS measurements and analyses; (b) the exceptional hardening during primary creep due to a fine dispersion of matrix carbides was verified by the SANS data and the corroborative TEM observations, 
(c) SANS measurements of creep-induced cavities were made by repeated measurement after post-creep solution heat treatment.

Direct TEM observations of carbide particles are generally in good agreement with the SANS data. However, the TEM studies indicated heterogeneous size and number distributions of precipitates, hence substantial variations from one field of view in a foll to anothe:. Even with the use of HVEM the direct observation of grain boundary cavities was found to be difficult because of this heterogeneous distribution and the low cavity density. To obtain a valid comparison to SANS data, which sampled a much larger volume of material than TEM observations, a large number of HVEM foil observations will be required. In order to obtain a rellable size distribution curve from SANS data obtained from creep deformation through the secondary stage and beyond, the uncertainty about the presence of a Gulnier region should be eliminated. This may be accomplished by measuring SANS intensity at sufficiently low Bragg angles. To investigate the nucleation and early growth of grain boundary cavities, which are induced by the time dependent stress concentrations during creep deformation (Chen and Argon, 1981; Yoo and Trinkaus, 1982), SANS measurements from samples deformed in the transient primary stage or by cyclic creep are desirable.

\section{ACKNOWLEDGMENT}

Research was sponsored by the Division of Materials Sclences, U. S. Department of Energy under Contract W-7405-eng-26 with the Union Carbide Corporation. We thank Drs. W. C. Koehler, H. R. Chi_... .. j. Lin, S. Spooner, and G. D. Wignall, Staff of the National Center for Small-Angle Scattering Research, for their invaluable assistance in 
performing this work. The NCSASR is sponsored by the National Sctence Foundation through an interagency agreement with the Department of Energy. 


\section{REFERENCES}

Chen, I. W., and A. S. Argon (1981). Acta Met., 29, 1321-33.

Fedorova, I. S., and P. W. Schmidt (1978). J. Appl Cryst., 11, 405-1.1.

Guinier, A. (1939). Ann. Phys. (Par1s), 12, 161-237.

Hendricks, R. W., J. Schelten, and W. Schmatz (1974). Phil. Mag., 30, 819-37.

Koehler, W. C., H. R. Child, R. W. Hendricks, J. S. Lin, and

G. D. Wignall (1981). Proc. of Symposium on Neutron Scattering

held at Argonne National Laboratory, Aug. 12-14, 1981.

Korstortz, G. (1979). Neutron Scattering. In Treatise on Materials

Science and Technology, 15, Academic Press, New York, pp. 227-89.

Porod, G. (1952). Kolloid Z., 125, 51-77, 109-22.

Schwahn, D., W. Kesternich, and H. Schuster (1981). Metall. Trans. 12A, $155-65$.

Swindeman, R. W. (1979). Contour Maps for Parameters Describing the

Temperature-Stress-Strain Behavior of Type 304 Stainless Steel (Heat

9T2796), ORNL Report-5473.

Weertman, J. R. (1981). Nondestructive Evaluation: Microstructural

Characterization and Reliability Strategies, ed by 0 . Buck and

S. M. Wolf, Spec. Publ. AIME, Pp. 147-68.

Yoo, M. H., J. C. Ogle, B. S. Borle, E. H. Lee, and R. W. Hendricks

(1982). Acta Met. to be published.

Yoo, M. H., and H. Trinkaus (1982). Metall. Trans. to be published. 


\section{EIGURE CAPTIONS}

Fig. 1. Creep curves for two specimens examined by SANS; (a) interrupted at the end of the secondary stage, (b) ruptured at $16,891 \mathrm{~h}$.

Fig. 2. TEM micrographs (a) after creep at $593^{\circ} \mathrm{C}, 134 \mathrm{MPa}$, and $12,100 \mathrm{~h}$, and (b) after post-creep solution heat treatment.

Fig. 3. Radially-averaged scattering intensity measured from the gage section of the sample crept through the secondary stage - Porod plot.

Fig. 4. Guinier plot showing the intensity in the forward direction, $I(0)$, and the radius of gyration, $R_{G}$.

Fig. 5. Size distribution of precipitates and cavities evaluated with the two phase model of small-angle scattering theory. 
ORNL-DWG 82-8873

CREEP CURVES FOR TWO TYPE 304 SS SPECIMENS

EXAMINED BY SANS

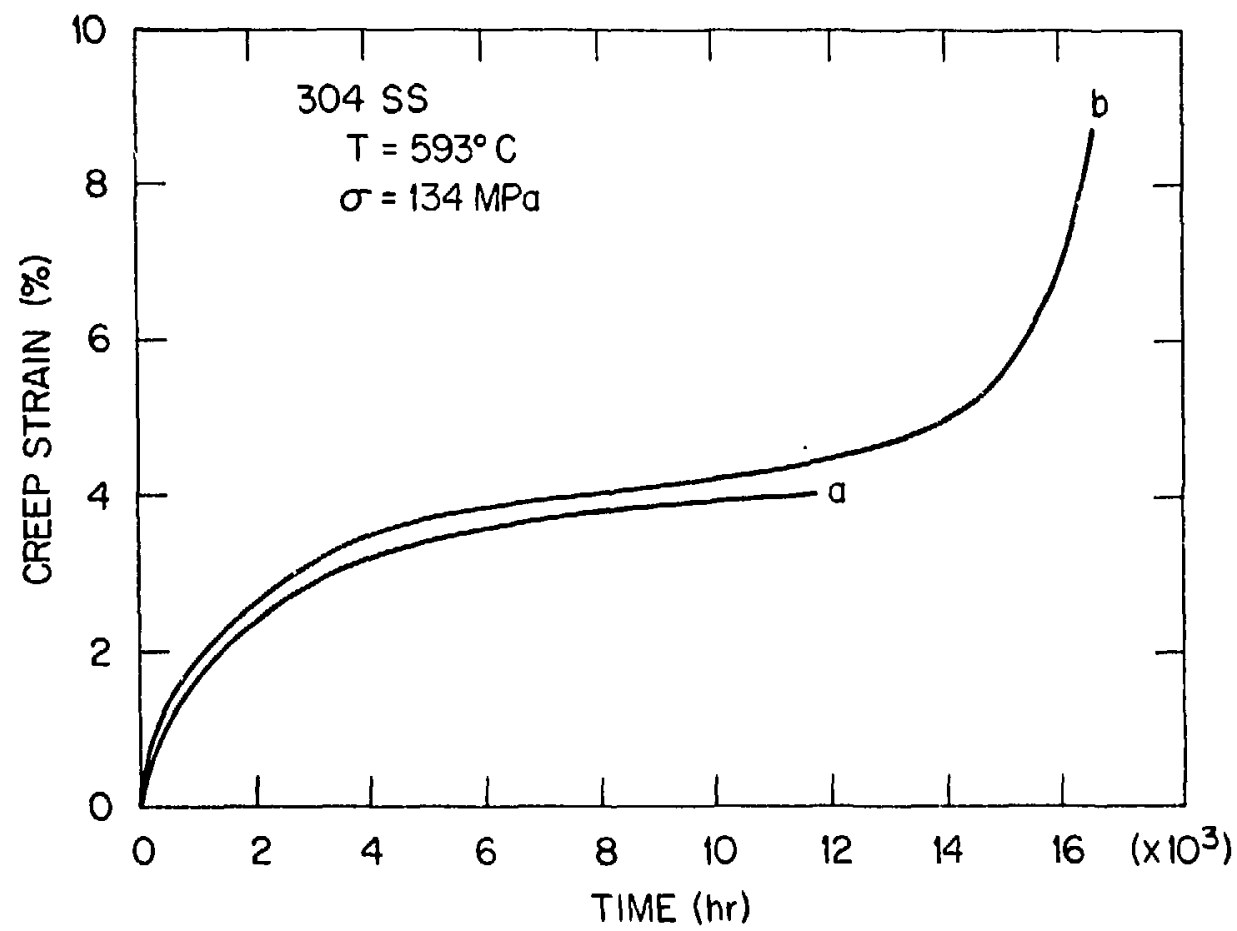

ig. 1 . 

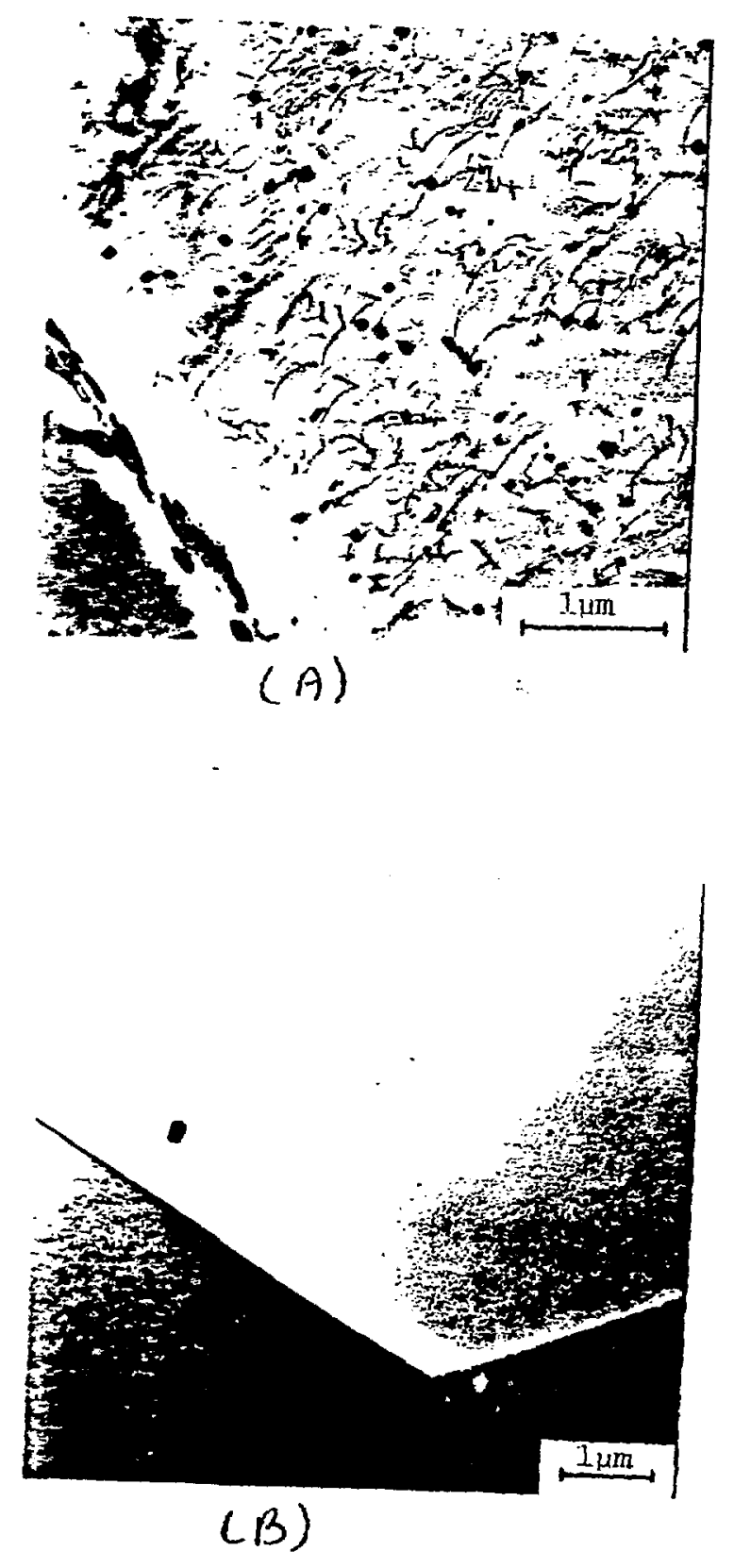


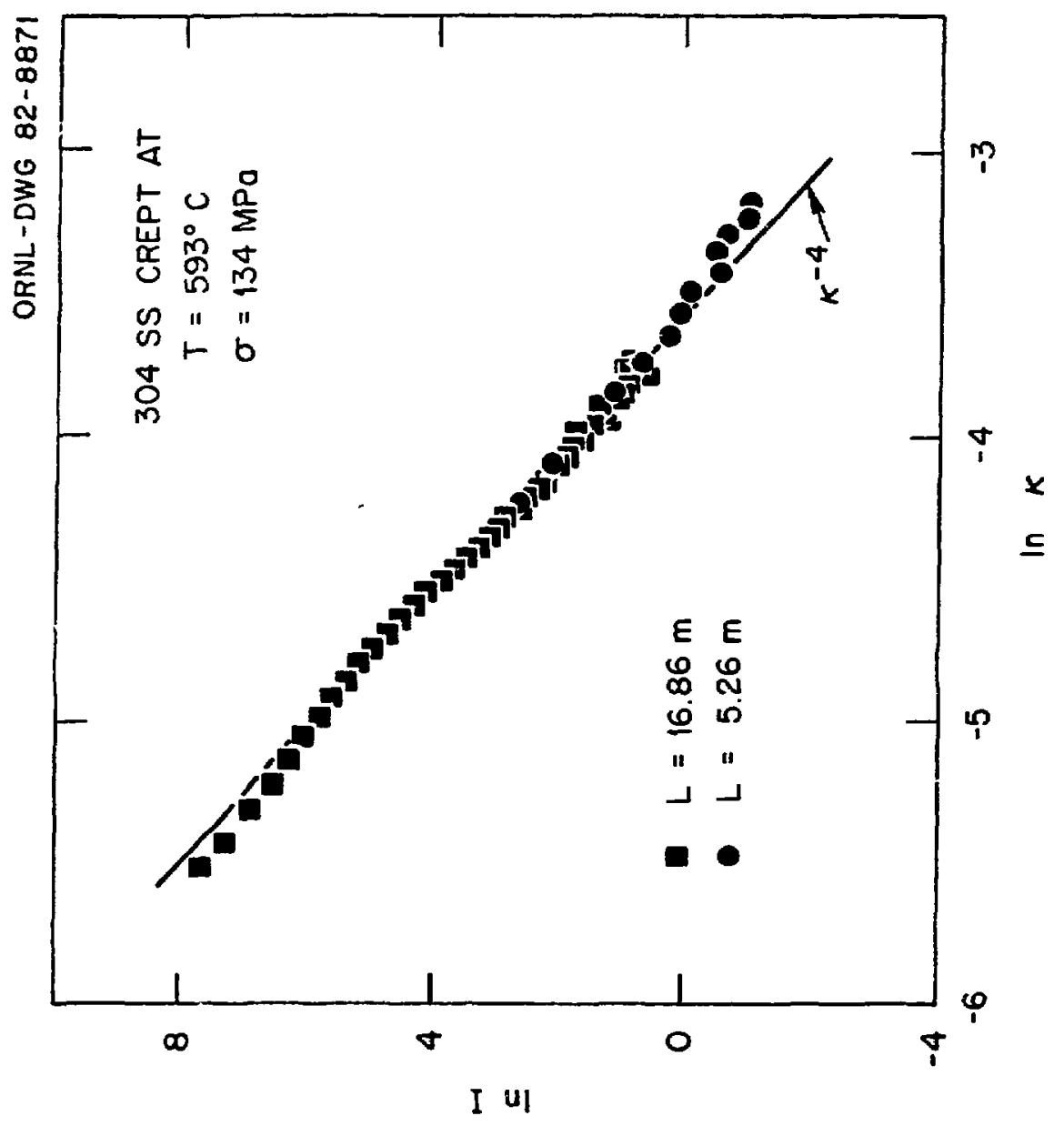

$\dot{\mu}^{m}$ 
ORNL - OWG 82-8870

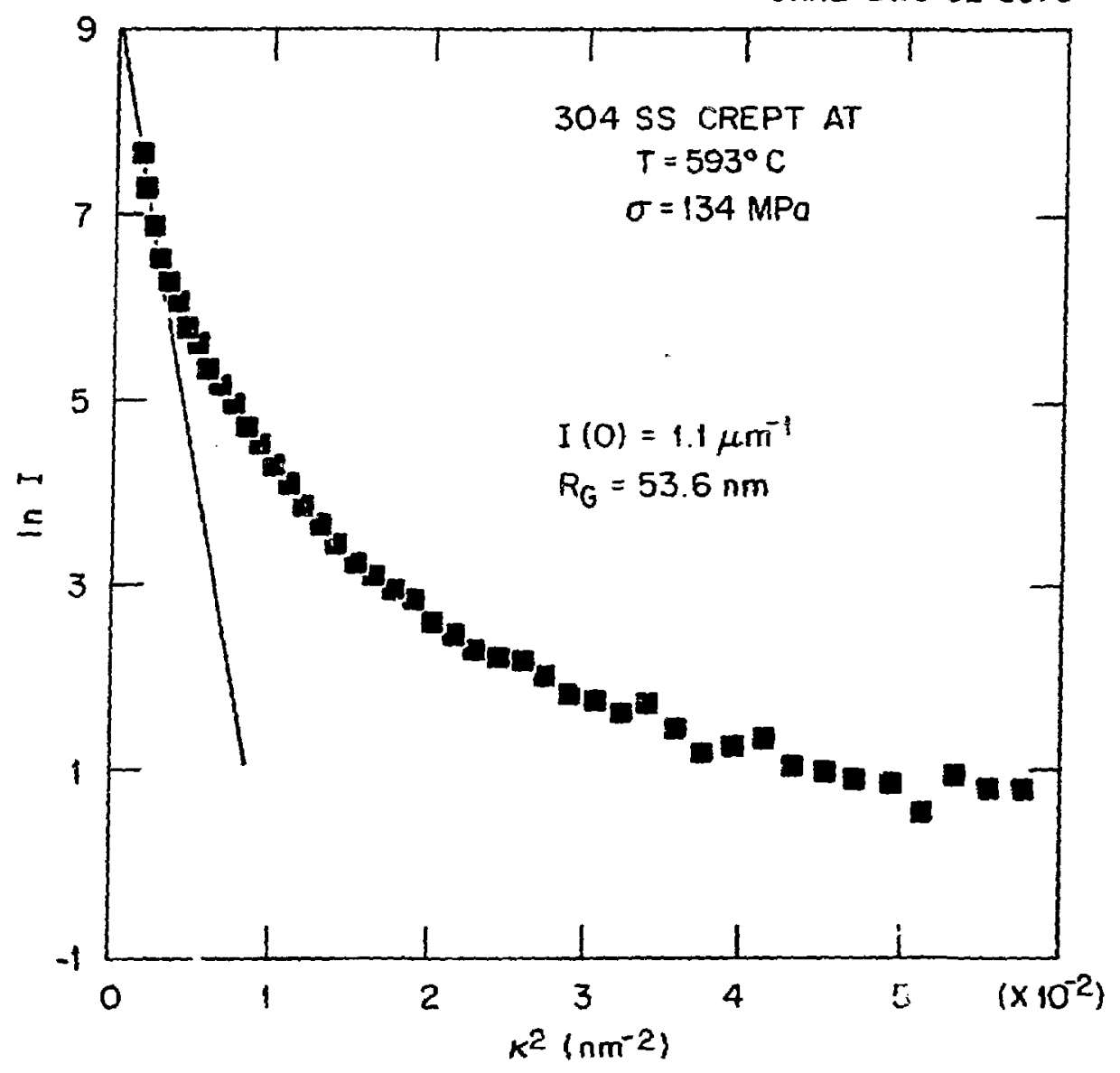




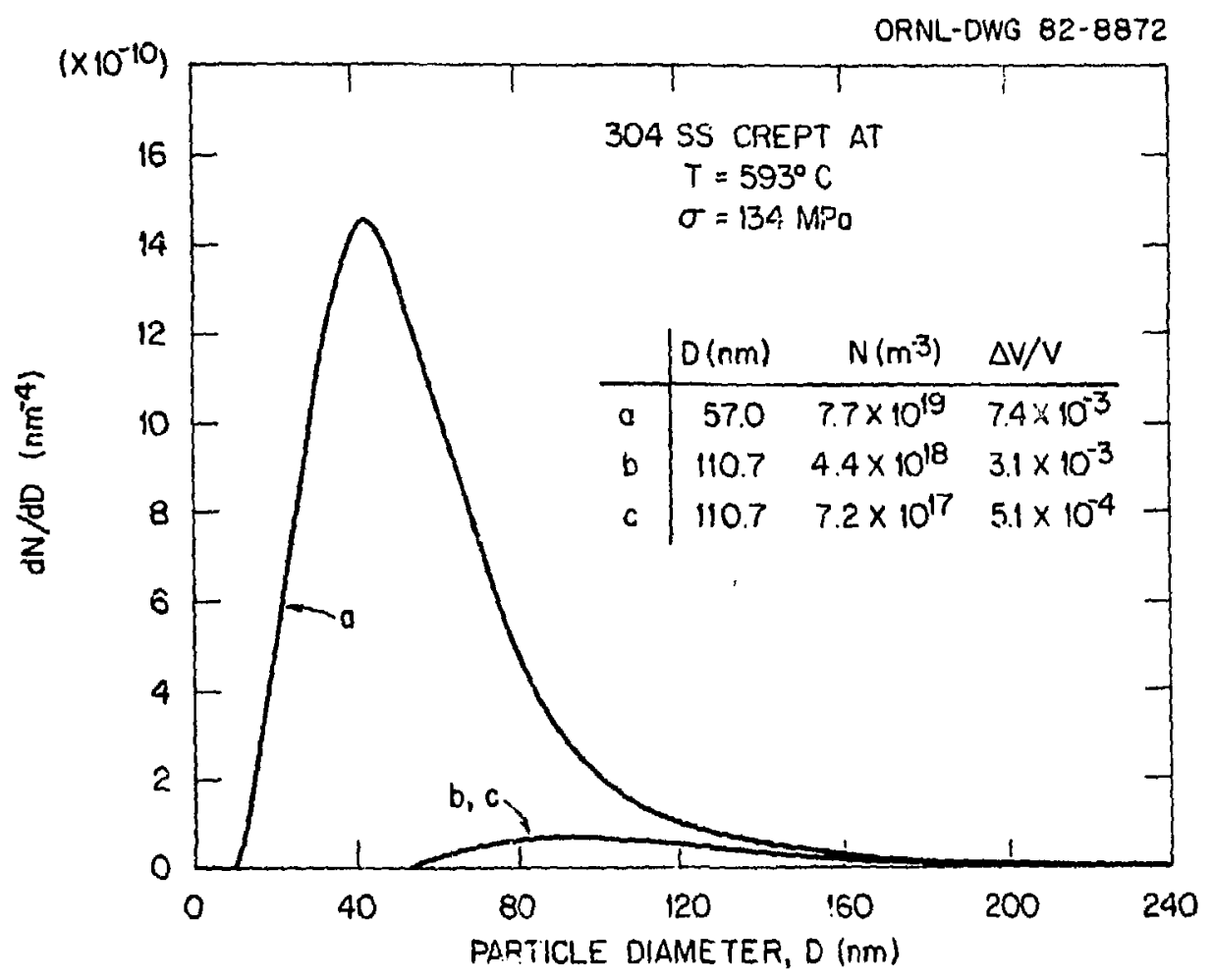

ig. 5 